DOI 10. 18307/2018. 0126

(c) 2018 by Journal of Lake Sciences

\title{
供给侧改革与科技创新塊合助推西藏渔业资源养护”
}

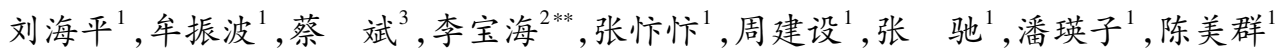 \\ $(1:$ 西藏自治区农牧科学院,水产科学研究所,拉萨 850002) \\ $(2:$ 西藏自治区农牧科学院, 拉萨 850002$)$ \\ (3:西藏自治区农牧厅,拉萨 850000$)$
}

\begin{abstract}
摘 要: 由于西藏生态环境脆弱、生态系统结构简单、生产力低下以及高原鱼类生长缓慢、资源补充周期长、对生境高度 适应和依赖等特点, 高原水域水生生态更容易受到外界的影响. 尤其近几十年以来, 外来鱼类人侵、水电水利设施的兴 建、过度捕拹、水质环境恶化, 导致 162 种青藏高原鱼类中, 处于极危、濒危、易危或野外绝灭鱼类就有 35 种,超过了 $20 \%$, 在雅鲁藏布江中游, 常见的 6 种裂腹鱼类中, 有 3 种鱼类处于濒危状态, 因此推动西藏渔业资源养护刻不容缓. 供给侧改 革和科技创新, 将为西藏渔业资源养护注入新的活力. 通过科学引导放生行为, 规范和加强增殖放流行为, 积累和推广本 土鱼类繁育技术, 密切关注西藏水生态系统, 将会推动西藏渔业资源养护工作迈上一个新台阶, 也会助推西藏“精准扶 贫”进程.
\end{abstract}

关键词: 供给侧改革;西藏;渔业资源;精准扶贫; 外来种; 青藏高原

\section{Coupling supply-side structural reform and technological innovation boosting the fishery resource conservation process in Tibet}

LIU Haiping ${ }^{1}$, MOU Zhenbo ${ }^{1}$, CAI Bin ${ }^{3}$, LI Baohai ${ }^{2 * *}$, ZHANG Bianbian ${ }^{1}$, ZHOU Jianshe ${ }^{1}$, ZHANG Chi ${ }^{1}$, PAN Yingzi ${ }^{1} \&$ CHEN Meiqun ${ }^{1}$

(1: Institute of Fisheries Science, Tibet Academy of Agricultural and Animal Husbandry Sciences, Lhasa 850002, P.R.China)

(2: Tibet Academy of Agricultural and Animal Husbandry Sciences, Lhasa 850002, P.R.China)

(3: Tibet Autonomous Region Agricultural and Pastoral Office, Lhasa 850000, P.R.China)

\begin{abstract}
In Tibet, owing to the characteristics of fragile eco-environment, simple ecosystem structure, low productivity, slow fish growth, long period of resource complement, high fitness and dependence on the environment, the hydro-ecology of rivers and lakes is vulnerable to external factors. Especially, under the condition of alien fish invasion, hydropower facilities construction, overfishing, water environment deterioration, 35 fish species are confronting critically endangered, endangered, vulnerable, or extinction condition in the wild, which exceeding 20\% of the total 162 fish species distributed in Tibetan Plateau. There are also 3 species confront endangered condition among 6 common Schizothorax fish species distributed in the middle reaches of Yarlung Zangbo River. Therefore, it is urgent to promote fishery resource conservation process in Tibet. Fortunately, supply-side structural reform and technological innovation will reinvigorate fishery resource conservation process. Through scientific guidance release behavior, specification and reinforcement fish stock enhancement behavior, accumulating and promoting breeding technology for native fish, closely focusing on hydro-ecology in Tibet, all these efforts will come to a new step for fishery resource conservation and promote targeted poverty alleviation process in Tibet.
\end{abstract}

Keywords: Supply-side structural reform; Tibet; fishery resource; poverty alleviation process; alien species; Tibetan Plateau

* 农业部公益性行业专项 (201403012)资助. 2017-01-21 收稿; 2017-05-06 收修改稿. 刘海平(1981 ), 男,博士 研究生,副教授; E-mail: luihappying@163.com.

** 通信作者; E-mail: lbh0891@163.com. 


\section{1 西藏渔业资源面临极大威胁, 渔业资源养护工作刻不容缓的现状}

近几十年来, 随着西藏社会经济的快速发展, 西藏鱼类资源也面临着国内其他水域渔业发展所出现的 一些共性问题,如部分流域过度捕捞 ${ }^{[1-5]}$ 、水利设施建设导致的大坝阻隔、栖息地丧失、生境片段化 ${ }^{[6]}$ 等. 而 且由于西藏特殊的地理位置和社会经济特点, 它还面临着更为严峻的生态环境问题和挑战, 如外来物种人 侵 ${ }^{[7-10]}$ 、全球气候变化 ${ }^{[11-12]}$ 等. 加之高原生态环境脆弱、生态系统结构简单、生产力低下 ${ }^{[13]}$ 以及鱼类生长缓 慢、资源补充周期长、对生境高度适应和依赖等特点 ${ }^{[2-5,14]}$, 西藏水生生态更容易受到外界的影响.

\section{1 外来鱼类入侵对西藏土著鱼类的影响}

在西藏, 每年的萨嘎达瓦节期间, 全区的藏族同胞都会从市场上购买活鱼, 并将其放生到河流中, 但由 于受到当地捕捞量的限制以及鱼贩子追求经济利益最大化的影响, 市场销售的鱼类绝大多数为内地养殖的 品种. 多年大量重复引人, 导致这些外来鱼类在西藏人口相对密集的城镇附近水域中形成了可以自我繁殖 的种群. 目前, 外来鱼类在西藏的一些水体中已经非常常见. 在尼洋河鱼类的调查 ${ }^{[7]}$ 中发现了鲫、麦穗鱼、泥 鲽、大鳞副泥鲉和黄黝鱼 5 个外来鱼类种群. 拉萨市拉鲁湿地 ${ }^{[8]}$ 共发现 7 种外来鱼类, 其中外来的麦穗鱼和 鲫已成为绝对优势种, 而 5 种土著鱼类的数量极少. 拉萨河流域 ${ }^{[9]}$ 外来的鲫、麦穗鱼、泥鱾、鲤、黄黝鱼、草鱼 和银鲫已占总渔获量的 $42.5 \%$. 外来鱼类与本土鱼类的竞争, 可能导致土著鱼类成鱼或者幼鱼的饵料资源 匮乏, 从而间接导致其种群数量下降 ${ }^{[10]}$, 从现有调查数据分析, 外来鱼类对西藏土著鱼类和生态系统已经产 生了影响.

\section{2 水电水利设施兴建将威胁西藏鱼类资源的可持续利用}

西藏水能资源十分丰富, 理论蕴藏量 $2.055 \mathrm{~kW}$, 约占全国的 $1 / 3$, 居全国首位 ${ }^{[16]}$, 可开发的水能资源位 居全国前列 ${ }^{[15-16]}$. 西藏经济要发展, 必须做好水资源这篇大文章 ${ }^{[16]}$. 虽然水电在满足能源需求、改善能源结 构、减少环境污染、促进经济发展等方面有着极其重要的作用,但是水电开发同样可能对生态环境产生负面 影响. 水电站的建设将会引起下游流速形态反应的改变 (Downstream Response to Imposed Flow Transformation, DRIFT), 这种改变是河流生态综合反应 ${ }^{[17]}$, 水流量节律变化是水电站建设过程中对水生生 态系统影响最为严重的环境因子 ${ }^{[18-19]}$, 其影响表现在 4 个方面 ${ }^{[20]}$ : 一是水流的变化将会严重影响河道形态 和泛滥平原生境; 二是水生生物将会调整生活史策略; 三是坝站的建设将会破坏依赖于经纬度生物的种群 交流; 四是水流的变化为外来种或者人侵种创造了便利环境. 西藏河流中的鱼类绝大部分为适应流水或急 流环境的种类, 如裂腹鱼亚科的裂腹鱼属、叶须鱼属, 野鲮亚科, 鲃亚科, 裸吻鱼科以及鮡科等, 均为典型的 适应流水性鱼类, 通常在峡谷河道的急流中生活, 水电水利设施的大规模建设将直接威胁这些特有鱼类的 生存和资源的可持续利用.

\section{3 过度捕捞导致西藏本土鱼类资源量急剧下降}

由于自然环境条件、宗教和生活习俗等原因, 在历史上青藏高原的绝大多数地区土著鱼类资源丰富. 目 前, 西藏大部分区域属于无人区或人烟稀少的牧区, 渔业资源开发仍处于原始状态. 但在一些经济发达的区 域, 如雅鲁藏布江中游, 拉萨河、尼洋河等水域已出现捕捞过量、鱼类小型化的现象. 雅鲁藏布江常见的 6 种 本土裂腹鱼类 ( 双须叶须鱼 (Ptychobarbus dipogo )、巨须裂腹鱼 (Schizothorax macropogon)、拉萨裂腹鱼 (Racoma waltoni) 、异齿裂腹鱼 (Racoma o'conori)、拉萨裸裂尻 (Schizopygosis younghusbandi) 和尖裸鲤 (Oxygymnocypris stewartii) ) 中已有 3 种 (巨须裂腹鱼、尖裸鲤和双须叶须鱼) 被列为濒危鱼类 ${ }^{[21]}$. 近 $20 \mathrm{a}$ 来的持 续渔业活动已经导致了西藏局部江段土著鱼类渔业资源衰退. 雅鲁藏布江中游部分河段的渔获物由开发初 期 (1990s) 平均体重 500 1000 g/尾下降到近年来的 300 500 g/尾; 2000 年以前, 拉萨河黑斑原鮡资源丰 富,平均体重较大, 而到 2010 年,在拉萨河已经难以捕到, 而且捕捞个体呈逐年减小趋势.

到目前为止, 西藏大部分土著鱼类仍为自然繁衍状态, 人工繁殖尚未完全取得成功, 而市场上对西藏土 著鱼类的需求日趋增多. 为了谋取更大的经济利益, 渔民采用小网目捕捞, 电鱼、炸鱼的恶性事件屡有发生. 在人口聚集的地区,这一现象尤为严重,雅鲁藏布江流域的主要裂腹鱼类资源量急剧下降.

\section{4 水质环境变化对西藏渔业资源造成潜在威胁}

尽管目前西藏的大型工业不多,对渔业资源和水域环境的危害尚未呈现. 但在人口相对密集的局部地 
区, 人类活动对西藏渔业环境的影响已经较为突出. 与 1996 年相比, 2010 年拉萨河流域非点源污染发生高 风险区域面积减少、低风险区域面积增加, 但是中等和较高风险区域面积有增加趋势 ${ }^{[22]}$. 在拉鲁湿地以下 河段, COD 污染超标严重, 最大倍数达 17.5 倍 ${ }^{[23]}$. 拉萨河流域部分水体未达到《地表水环境质量标准》(GB 3838-2002) III 类水质标准 ${ }^{[24]}$. 通过对农业生产中的化肥和农药施用量、养殖业发展增加的牲畜养殖量, 以 及生活污水的增加量、排放量、污染负荷贡献量的分析, 王洪亮指出尼洋河流域面临着农业、畜禽养殖和生 活污水等污染问题 ${ }^{[25]}$. 汪艳青等认为西藏农村社会经济发展水平相对较低, 公共基础设施建设相对落后, 农民收人相对较低, 农民环保意识较差, 西藏农村水环境呈现日益恶化趋势 ${ }^{[26]}$. 此外, 矿山开发 ${ }^{[27-28]}$ 和生活 垃圾的填埋 ${ }^{[29]}$ 也都会对西藏区域水环境产生影响. 这些情况说明, 在人类干扰不断加剧的情况下,西藏局 部地区的水环境现状不容乐观, 西藏 2013-2017 年水资源生态盈余呈下降趋势 ${ }^{[30]}$. 因此, 必须密切关注流 域水质环境的变化对西藏渔业资源造成的潜在威胁.

\section{5 西藏鱼类资源特点警示要加快鱼类资源保护工作}

西藏鱼类资源最显著的特点是组成简 ${ }^{-}{ }^{[31-32]}$, 裂腹鱼亚科和条鲉科高原鱾属鱼类构成了西藏河流及湖 泊鱼类区系的主体; 特别是在高原腹地的藏北高原, 只存在这两个类群的鱼类; 而适应急流环境而特化的鮡 科和野鲮亚科鱼类, 除原鮡属鱼类外, 仅分布于高原南部和东南部边缘; 其次是西藏各河流之间的鱼类组成 存在着明显的种属差别, 特有程度高. 由于河流的深切和长期剥蚀, 各河流间鱼类长期隔离, 演化出特有种 甚至是特有属, 如: 长江水系的 22 种裂腹鱼中, 18 种为西藏特有种, 在雅鲁藏布江中上游及毗邻水系的 7 种 中, 4 种为该区所特有, 另有 2 个多型种分化成 5 个亚种, 均为西藏所特有. 其他水系的特有种也至少占各自 鱼类种数的 $50 \%$ 以上.

青藏高原鱼类是长期适应高原环境而形成的特殊类群. 一方面, 高原严酷的自然环境条件, 如环境温度 低、饵料生物贵乏、水文过程中水体理化因子变化明显, 决定了西藏土著鱼类具有生长缓慢, 性成熟晚、繁殖 力低等的生物学特性 ${ }^{[2-5,14,33]}$. 高原土著鱼类资源一旦濒危, 其种群数量很难得到恢复. 另一方面, 在长期的 演化过程中, 高原土著鱼类之间形成了简单且相对稳定的种间关系. 而外界的干扰, 如外来种的人侵和过度 捕捞很容易使这种种间关系受到破坏, 给高原水体生态系统,特别是土著鱼类带来灾难性的后果.

\section{2 构建“青山绿水”的“生态西藏”,需要开展西藏渔业资源养护}

西藏自治区位于我国西南边疆的青藏高原, 面积 120 多万平方公里, 约占全国总面积的八分之一. 被誉 为 “地球的第三极” 的青藏高原地势高峻, 是我国重要的生态屏障和安全屏障. 西藏河流纵横交错, 湖泊星 罗密布, 水系格局极为复杂, 是我国河流数最多、湖泊面积最大、国际河流分布最广的省区 ${ }^{[15]}$. 因此, 西藏是 我国乃至南亚最重要的水源地,是我国极其重要的水资源安全战略基地和水能资源基地.

\section{1 国家发展的需求,需要开展西藏渔业资源养护}

2016 年 8 月 22-24 日习近平总书记在青海考察时强调“尊重自然、顺应自然、保护自然, 坚决筑牢国家 生态安全屏障” ${ }^{[34]}$. 习近平总书记在中央第六次西藏工作座谈会上指出 ${ }^{[35]}$, 要坚持生态保护第一, 采取综合 举措, 加大对草地、湿地、天然林的保护力度. 为贯彻落实中央第六次西藏工作座谈会精神, 2016 年 3 月全国 渔业渔政工作会上 ${ }^{[36]}$, 韩长赋部长提出 “青藏高原生态环境脆弱, 重点是保护水生生物资源和生态环境”. 同时在 7 月西藏拉萨召开了全国农业援藏工作座谈会 ${ }^{[37]}$, 韩长赋部长强调援藏工作要抓好“五突出、五促 进”. 在农业部与西藏自治区部、省会商中, 将“西藏重点水域渔业资源调查”专项列为农业部重点农业援藏 项目, 并且将于 2017 年组织实施 ${ }^{[38]}$. 而且水生生物资源本底及多样性调查是 2010 年国务院颁布的《中国生 物多样性保护战略与行动计划》 $(2011-2030$ 年) 中制定的优先行动和项目.

西藏是我国内陆水体极为丰富的地区 ${ }^{[15]}$, 自 1965 年以来, 虽然渔业产值对数增长幅度呈直线增长 (图 1), 但是渔业产值占生产总值比例最大值也没有超过 $1 \%$, 渔业产值占农林牧渔产值的比例也未及 $2.5 \% 0$ (表 1), 与此不相适应的是近年来西藏对水产品的消费持续增加, 而当地渔业产品远远无法满足市场的需求. 据 不完全统计, 西藏各大农贸市场销售的内地养殖鱼类占到 30\% 50\%, 这还不包括餐饮行业直接从内地调人 的各类水产品. 


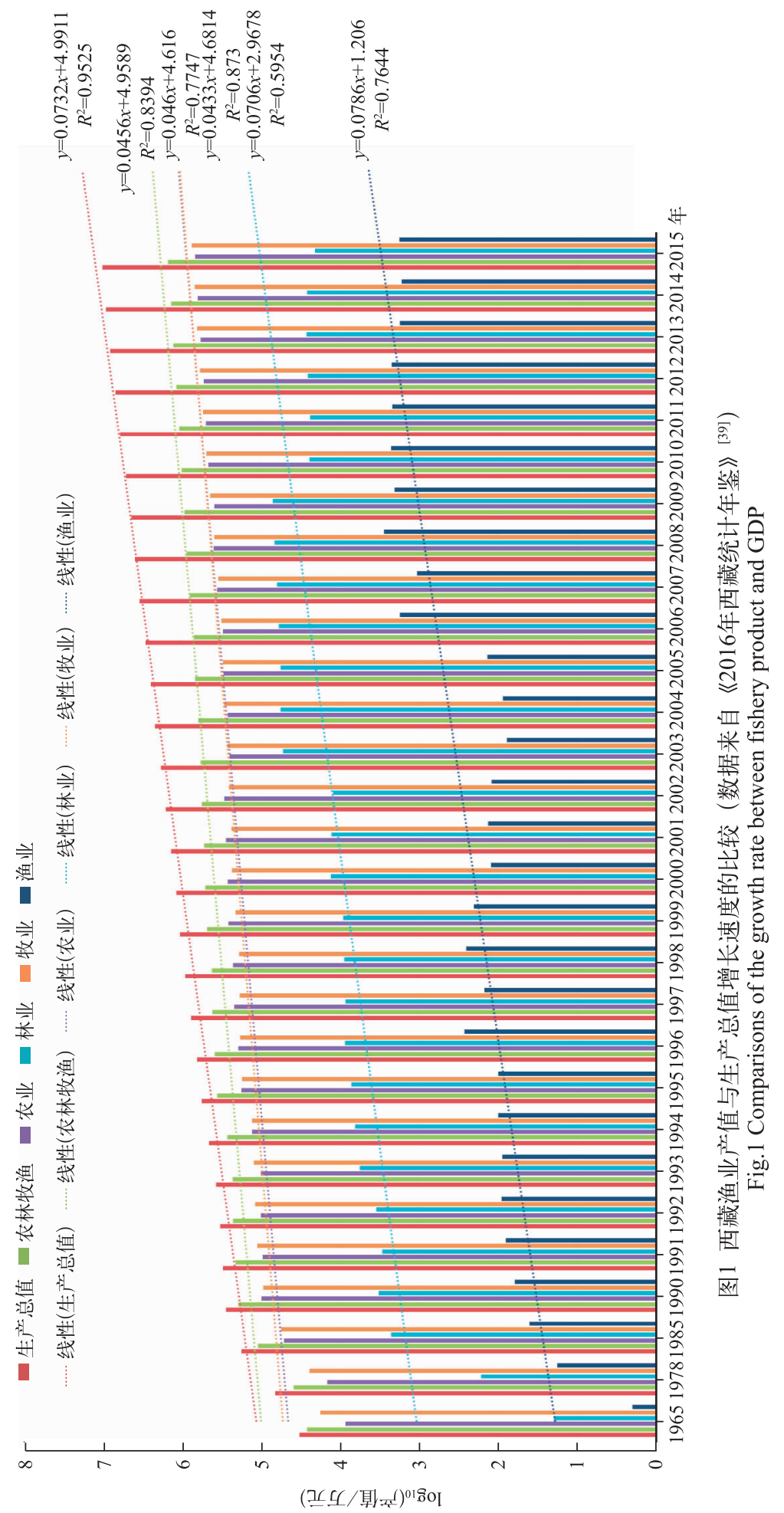


表 1 西藏渔业产值、农林牧渔产值与生产总值的比较”

Tab.1 Comparison of the growth rate among fishery product, the total product of agriculture, forestry, animal \& husbandry and fishery and GDP in Tibet

\begin{tabular}{|c|c|c|c|c|c|}
\hline 年份 & $\begin{array}{l}\text { 生产总值/ } \\
\text { 万元 }\end{array}$ & $\begin{array}{c}\text { 农林牧渔产值/ } \\
\text { 万元 }\end{array}$ & $\begin{array}{c}\text { 渔业产值/ } \\
\text { 万元 }\end{array}$ & $\begin{array}{c}\text { 渔业产值/生产总值/ } \\
\left(\times 10^{-4}\right)\end{array}$ & $\begin{array}{c}\text { 渔业产值/农林牧渔产值/ } \\
\left(\times 10^{-4}\right)\end{array}$ \\
\hline 1965 & 32700 & 26420 & 2 & 0.61 & 0.76 \\
\hline 1978 & 66500 & 39228 & 18 & 2.71 & 4.59 \\
\hline 1985 & 177600 & 108875 & 40 & 2.25 & 3.67 \\
\hline 1990 & 277000 & 195023 & 62 & 2.24 & 3.18 \\
\hline 1991 & 305300 & 210063 & 81 & 2.65 & 3.86 \\
\hline 1992 & 332900 & 224530 & 90 & 2.70 & 4.01 \\
\hline 1993 & 374200 & 229860 & 89 & 2.38 & 3.87 \\
\hline 1994 & 459900 & 268249 & 100 & 2.17 & 3.73 \\
\hline 1995 & 561100 & 358961 & 101 & 1.80 & 2.81 \\
\hline 1996 & 649800 & 385282 & 269 & 4.14 & 6.98 \\
\hline 1997 & 772400 & 414546 & 150 & 1.94 & 3.62 \\
\hline 1998 & 915000 & 423770 & 253 & 2.77 & 5.97 \\
\hline 1999 & 1059800 & 482155 & 202 & 1.91 & 4.19 \\
\hline 2000 & 1178000 & 512185 & 124 & 1.05 & 2.42 \\
\hline 2001 & 1391600 & 527791 & 134 & 0.96 & 2.54 \\
\hline 2002 & 1620400 & 558874 & 122 & 0.75 & 2.18 \\
\hline 2003 & 1850900 & 586339 & 78 & 0.42 & 1.33 \\
\hline 2004 & 2203400 & 627373 & 87 & 0.39 & 1.39 \\
\hline 2005 & 2488000 & 677408 & 136 & 0.55 & 2.01 \\
\hline 2006 & 2907600 & 704765 & 1762 & 6.06 & 25.00 \\
\hline 2007 & 3414300 & 798309 & 1073 & 3.14 & 13.44 \\
\hline 2008 & 3948500 & 884518 & 2804 & 7.10 & 31.70 \\
\hline 2009 & 4413600 & 933807 & 2049 & 4.64 & 21.94 \\
\hline 2010 & 5074600 & 1007685 & 2268 & 4.47 & 22.51 \\
\hline 2011 & 6058300 & 1093675 & 2181 & 3.60 & 19.94 \\
\hline 2012 & 7010300 & 1183267 & 2220 & 3.17 & 18.76 \\
\hline 2013 & 8156700 & 1279967 & 1762 & 2.16 & 13.77 \\
\hline 2014 & 9208300 & 1387236 & 1676 & 1.82 & 12.08 \\
\hline 2015 & 10263900 & 1494633 & 1774 & 1.73 & 11.87 \\
\hline
\end{tabular}

* 数据来源于文献 $[39]$.

西藏本土冷水性土著鱼类肉质细嫩鲜美, 富含不饱和脂肪酸, 是优质的动物蛋白来源 ${ }^{[0-42]}$, 也是潜在的 名优养殖品系. 然而, 目前我们对西藏全区鱼类资源的分布现状、面临的问题以及其生物学、生态学和遗传 学基本特征的了解还不够深人. 而这些渔业基础工作是今后开发利用、保存种质资源 (遗传和活体) 以及挖 掘新的遗传性状的前提. 因此, 通过开展西藏渔业资源养护, 不仅可以通过人工养殖增加渔业产量以满足西 藏当地对优质水产品的需求, 还可以减少对自然鱼类资源的捕捞; 同时, 通过人工增殖放流补充自然资源, 达到保护和合理地利用西藏渔业资源的目的,这对促进西藏社会经济的可持续发展具有重要的现实意义.

\section{2 保障生态西藏建设, 需要开展西藏渔业资源养护}

水生生物是水生生态系统中最为重要的组成部分, 是水生生态系统生命形式的体现, 也是生态系统内 部进行能量流动、物质循环和信息传递的载体. 淡水生态系统与人类活动密切相关, 人类不仅利用淡水和水 生生物资源, 而且直接或间接将人类活动产生的废弃物转移到淡水系统中 ${ }^{[43]}$. 因此, 淡水系统也比其他生 态系统更容易受到威胁. 保护渔业资源及其依赖的淡水生态系统的前提是充分了解水生生物现状以及面临 
的威胁. 然而, 除了少部分关于鱼类的物种分布 ${ }^{[1,7,9,31-32]}$ 、部分本土鱼类生物学特性 ${ }^{[2-5,14,44-49]}$ 和部分水域水 环境特征的研究之外 ${ }^{[50-55]}$, 西藏大部分水体仍缺乏详细的基础环境数据和渔业生物学数据. 有关西藏鱼类 最近的调查距今已有 20 多年 ${ }^{[32]}$, 而这 $20 \mathrm{a}$ 也正是西藏社会经济快速发展的时期. 在当前渔业自然资源持 续下降、外来物种人侵和人类活动加剧的背景下, 西藏生态环境只能优化、不能恶化, 必须树立尊重自然、顺 应自然、保护自然的生态文明理念. 开展西藏渔业资源养护工作, 是指导西藏水资源规划和合理利用、保护 水生生物资源和保障生态西藏建设.

\section{3 供给侧改革和科技创新的耦合将助推西藏渔业资源养护进程}

中央农村工作会议 2015 年 12 月 24-25 日在北京召开. 会议强调, 要着力加强农业供给侧结构性改革, 提高农业供给体系质量和效率, 使农产品供给数量充足、品种和质量契合消费者需要, 真正形成结构合理、 保障有力的农产品有效供给. “农业供给侧结构性改革” 这一新鲜表述, 通过中国最高级别的“三农”会议, 首度进人公众视野.

国家发展改革委农经司司长吴晓 ${ }^{[56]}$ 指出: 提升生态安全保障能力, 促进资源永续利用. 确立发展绿色 农业保护生态的观念, 来推动农业可持续发展, 要加快形成资源利用高效、生态系统稳定、产地环境良好、产 品质量安全的农业发展新格局. 中国社科院农村发展研究所李国祥研究员说 ${ }^{[57]}$ : 创新主要体现在农业科技 创新、培育新型职业农民、适度规模经营等方面. 绿色则体现在对“加强资源保护和生态修复, 推动农业绿色 发展”的部署上.

西藏“十三五” 规划 ${ }^{[58]}$ 明确指出 “强化江河源头区、重要高原湖泊、水源涵养区和湿地生态保护,保持河 流湖库水系完整……深人实施生物多样性保护战略与行动计划, 加强生物多样性保护优先区域监管. 对濒 危野生动植物实施抢救性保护和救护繁育中心, 建立监测评估与预警体系, 严防物种资源丧失和外来物种 人侵”. 事实上, 在 162 种青藏高原鱼类中 ${ }^{[12,21]}$, 处于极危、濒危、易危或野外绝灭鱼类就有 35 种 $^{[6]}$, 超过了 $20 \%$ (表 2 ).

因此,西藏渔业资源养护的重要性和必要性可窥一斑,供给侧改革和科技创新将为其注人活力.

\section{1 科学引导放生行为, 助推西藏渔业资源养护进程}

通过新闻媒体、社会公益组织、个人力量多方位、多渠道宣传科学放生的重要性, 认识哪些鱼类应该放 生、放生在什么地方、什么时候最合适、如何辨识本土鱼类和外来鱼类等. 遵循“高原水养高原鱼” 的原则, 只 放本土鱼类, 不放外来鱼类 (表 3). 具体原则为: (1) 运输鱼类从鱼市到放生点时, 保证有充足的氧气, 温度 不宜过高 (不超过 $16^{\circ} \mathrm{C}$ ), 尽量避光, 如果路途较远, 要在中途做好换水准备; (2) 放生时要确认运输鱼类的 水温和待放生水体的水温温差在 $3^{\circ} \mathrm{C}$ 之内, 避免因温度不适, 导致鱼类应激反应而死亡; (3) 放生人工培养出 来的本土鱼苗或者成鱼, 因为这些鱼苗才会真正补充自然界鱼类资源; (4)大个体的鱼类放生在有大石头的 水域,这样鱼类可以刮食石头上的泥巴, 同时也可以在石头缝里休息; (5) 小个体的鱼类,放生在有鹅卵石的 水域, 这样的水体水流不是很快, 同样可以刮食石头上的泥巴, 还可以躲藏在鹅卵石缝间, 躲避紫外线的直 射和天敌对它们的攻击.

\section{2 规范和加强增殖放流行为, 助推西藏渔业资源养护进程}

西藏有记录的公益性增殖放流活动始于 2009 年, 随后每年都组织多次增殖放流活动. 放流活动的组织 单位涵盖了政府机关、高校、企业等多种机构. 放流的种类均为西藏珍稀特有的土著鱼类,包括黑斑原鮡 (Glyptosternum maculatum Regan)、亚东鲭( Salmon trutta fario Linnaeus)、尖裸鲤、双须叶须鱼、拉萨裸裂尻鱼、 拉萨裂腹鱼、巨须裂腹鱼、异齿裂腹鱼等. 2009-2016 年累计增殖放流的土著鱼类总数量超过 828 万尾, 已 经形成了一定的规模 ${ }^{[59]}$.

为进一步贯彻落实《中国水生生物资源养护行动纲要》, 促进水生生物增殖放流事业科学有序发展, 在 《农业部关于做好 “十三五” 水生生物增殖放流工作的指导意见》里提出 ${ }^{[60]}$, 计划到 2020 年, 西藏共需增殖 放流内陆经济物种 1000 余万尾, 珍稀濒危物种 200 余万尾, 主要增殖放流淡水经济物种 (区域性物种), 包 括西藏的高原裸裂尻、拉萨裸裂尻、双须叶须鱼、裸腹叶须鱼; 主要增殖放流珍稀濒危物种,包括西藏的尖裸 鲤、澜沧裂腹鱼、拉萨裂腹鱼、巨须裂腹鱼、黑斑原鮡. 国务院印发《“十三五”生态环境保护规划》指出 ${ }^{[61]}$, 要 
表 2 青藏高原受威胁鱼类*

Tab.2 Threatened fish species in Tibetan Plateau

\begin{tabular}{|c|c|}
\hline 鱼类名称 (拉丁名) & 评估类别 \\
\hline 四川哲罗鲑( Hucho bleekeri Kinura) & EN \\
\hline 拟鲶高原鲉( Triplophysa siluroides Herzenstein) & VU \\
\hline 黄河雅罗鱼( Leuciscus chuanchicus Kessler) & $\mathrm{VU}$ \\
\hline 小裂腹鱼 (Schizothorax parva Tsao) & EW \\
\hline 宁蒗裂腹鱼 (Schizothorax ninglangensis Wang et al) & EN \\
\hline 小口裂腹鱼 $($ Schizothorax microstoma Huang) & $\mathrm{EN}$ \\
\hline 大理裂腹鱼( Schizothorax taliensis Regan) & EN \\
\hline 厚唇裂腹鱼 (Schizothorax labrosa Wang et al) & $\mathrm{EN}$ \\
\hline 长须裂腹鱼 (Schizothorax longibarba Fang) & $\mathrm{CR}$ \\
\hline 灰色裂腹鱼 ( Schizothorax grisea Pellegrin) & $\mathrm{EN}$ \\
\hline 澜沧裂腹鱼 (Schizothorax lantsangensis Tsao) & $\mathrm{EN}$ \\
\hline 拉萨裂腹鱼 (Schizothorax waltoni Regan) & EN \\
\hline 西藏裂腹鱼 (Schizothorax labiata McClelland) & $\mathrm{VU}$ \\
\hline 巨须裂腹鱼 (Schizothorax macropogon Regan) & EN \\
\hline 塔里木裂腹鱼 (Schizothorax biddulphi Günther) & $\mathrm{CR}$ \\
\hline 昆明裂腹鱼 (Schizothorax grahana Regan) & $\mathrm{VU}$ \\
\hline 长丝裂腹鱼 (Schizothorax dolichonema Herzenstein) & $\mathrm{EN}$ \\
\hline 异齿裂腹鱼 (Schizothorax o'connori Llord) & EN \\
\hline 新疆扁吻鱼(Aspiorhynchus laticeps Day) & EN \\
\hline 裸腹叶须鱼 (Ptychobarbus kaznakori Nikolsky) & $\mathrm{VU}$ \\
\hline 中甸叶须鱼 (Ptychobarbus chungtienensis Tsao) & EN \\
\hline 厚唇裸重唇鱼 (Gymnodiptychus pachycheilus Herzenstein) & EN \\
\hline 全裸裸重唇鱼(Gymnodiptychus integrigymnatus Huang) & $\mathrm{CR}$ \\
\hline 青海湖裸鲤 (Gymnocypris przewalskii Kessler) & EN \\
\hline 斜口裸鲤 (Gymnocypris scolistomus Wu et Chen) & $\mathrm{VU}$ \\
\hline 高原裸鲤( Gymnocypris waddellii Regan) & $\mathrm{VU}$ \\
\hline 尖裸鲤 (Oxygymnocypris stewartii Lloyd) & EN \\
\hline 骨唇黄河鱼 (Chuanchia labiosa Herzenstein) & $\mathrm{VU}$ \\
\hline 极边扁咽齿鱼 (Platypharodon extremus Herzenstein) & $\mathrm{VU}$ \\
\hline 平鲔裸吻鱼 (Psilorhynchus homaloptera Hora et Mukerji) & $\mathrm{EN}$ \\
\hline 黑斑原鮡( Glyptosternum maculatum Regan) & EN \\
\hline 青石爬鮡( Euchiloglanis davidi Sauvage) & CR \\
\hline 黄石爬鮡( Euchiloglanis kishinouyei Kimura) & EN \\
\hline 中华鮡 ( Pareuchiloglanis sinensis Hora et Silas) & $\mathrm{EN}$ \\
\hline 细尾鮡( Pareuchiloglanis gracilicaudata Wu et Chen) & EN \\
\hline
\end{tabular}

* CR : 极危; $\mathrm{EN}$ : 濒危; $\mathrm{VU}$ : 易危; $\mathrm{EW}$ : 野外绝灭. 数据来源于文献 $[6]$.

对“野生动植物实施濒危抢救性保护”.

截至目前, 增殖放流技术规范不健全和效果评估重视程度不够等因素, 制约着西藏鱼类资源养护的进 程. 通过供给侧改革和科技创新活动, 建立西藏鱼类增殖放流与效果评估技术规范. 制定适宜西藏地区的增 殖放流与效果评估技术规范, 更好地引导和规范西藏地区增殖放流活动的开展, 提高增殖放流的质量. 同 时, 重视放流后的管理与评估工作. 管理部门一方面加强监督执法, 除必要的标记回捕研究之外, 严禁在放 流水域进行捕捞活动, 避免出现 “一边放流, 一边捕捞” 的恶性循环; 另一方面加强效果评估工作力度, 尤其 是加强标记回捕等效果评估研究, 以便指导增殖放流工作的改进方向. 


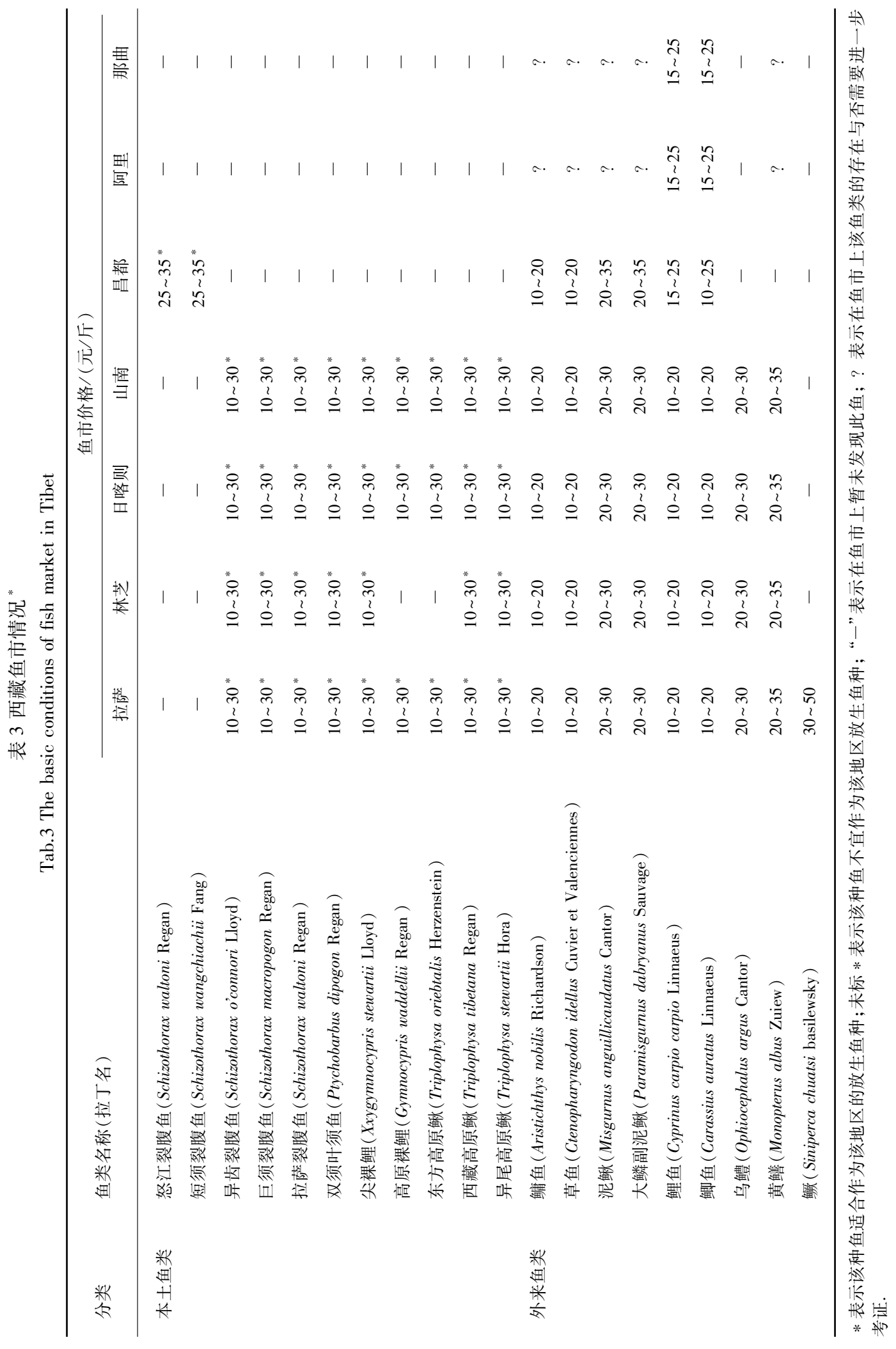




\section{3 积累和推广本土鱼类繁育技术, 助推西藏渔业资源养护进程}

虽然, 部分研究工作者对西藏本土鱼类的繁育技术付出了努力 ${ }^{[62-64]}$,但是繁育技术不稳定,种质资源保 种和市场推广还具有一定的风险, 部分繁育技术仍存在瓶颈问题, 如: 鱼病的防控、幼苗饲料的研发、西藏本 土鱼类繁育设施的研制、成鱼驯化技术的积累等, 通过供给侧改革和科技创新, 突破和积累西藏本土鱼类繁 育关键技术, 必将助推西藏渔业资源养护进程.

\section{4 密切关注西藏水生态系统, 助推西藏渔业资源养护进程}

国务院印发《“十三五”生态环境保护规划》明确指出 ${ }^{[61]}$, 生态环境是全面建成小康社会的突出短板, 要 加大保护力度, 强化生态修复, 保护生物多样性. 到 2020 年, 基本摸清生物多样性保护优先区域本底状况. 完善生物多样性观测体系, 开展生物多样性综合观测站和观测样区建设. 对重要生物类群和生态系统、国家 重点保护物种及其栖息地开展常态化观测、监测、评价和预警. 重要江河湖泊水功能区水质达标率从 2015 年的 $70.8 \%$ 提升到 2020 年的 $80 \%$ 以上.

因此,通过供给侧改革和科技创新, 形成长期的西藏水生态基础数据库, 如: 水环境和水生生物, 掌握西 藏本土鱼类的繁殖习性, “三场一通道” 等基本生物学特性, 为 “鱼类种质资源保护区”、“水电站开发”、“渔 业监测站”等项目的建设评估提供理论依据,这些努力将助推西藏渔业资源养护进程.

\section{5 开展西藏渔业资源养护工作,助推西藏“精准扶贫”进程}

西藏湖泊和河流有鱼水面总面积为 $16149.9 \mathrm{~km}^{2}$, 湖泊鱼蕴藏量为 $136869.705 \mathrm{t}$, 江河为 $4060.95 \mathrm{t}^{[32]}$, 由 于西藏高原鱼类生长缓慢、繁殖力低、性成熟晚等生物学特点, 根据 “适度干扰理论” ( Intermediate Disturbance Hypothesis, IDH ${ }^{[65-66]}$, 在保证既不损害资源, 又有稳定的产量的基础上, 开发量可以按照资源蕴 藏量的 $1 / 10$ 进行计量, 因此, 湖泊开发量建议为 $13687 \mathrm{t}$, 河流的开发量建议为 $406 \mathrm{t}$.

按照市场均价 4 万元 $/ \mathrm{t}$ 计算, 西藏湖泊鱼类蕴藏价值为 547478.82 万元, 每年可开发价值为 54748 万 元; 河流鱼类蕴藏价值为 16243.8 万元, 每年可开发价值为 1624 万元 ${ }^{[32]}$. 洛桑江村在 2016 年 1 月 27 日西藏 自治区政府工作报告指出 “坚决打赢脱贫攻坚战. 实施好全区脱贫攻坚规划, 完善专项、行业、社会、金融、援 藏“五位一体” 大扶贫格局” ${ }^{[67]}$. 因此, 可以根据当地水域面积和鱼类资源情况, 科学引导、合理开发鱼类资 源 (表 4), 迎合旅游消费群体口味, 将西藏鱼类产品打造成为绿色健康产品, 从而辐射带动当地的旅游产业 及老百姓就业问题,助推西藏“精准扶贫”进程.

表 4 西藏部分湖泊鱼类开发的经济价值*

Tab.4 Exploration economic value of some lakes in Tibet

\begin{tabular}{|c|c|c|c|c|}
\hline 湖泊 & 面积 $/ \mathrm{hm}^{2}$ & 所属行政区 & 产量/( $\left.\mathrm{kg} / \mathrm{hm}^{2}\right)$ & 年均开发价值/万元 \\
\hline 错鄂 & 6000 & 那曲县 & 140.00 & 336 \\
\hline 羊卓雍错 & 63800 & 浪卡子县 & 108.21 & 2761 \\
\hline 格仁错 & 46600 & 申扎县 & 115.22 & 2148 \\
\hline 班公错 & 41300 & 日土县 & 119.40 & 1973 \\
\hline 佩枯错 & 30000 & 吉隆、聂拉木县 & 77.61 & 931 \\
\hline 错鄂 & 24400 & 申扎县 & 81.94 & 800 \\
\hline 扎日南木措 & 11000 & 错勤县 & 67.16 & 296 \\
\hline 然乌措 & 2200 & 八宿县 & 137.31 & 121 \\
\hline 白湖 & 15000 & 边坝县 & 121.27 & 728 \\
\hline
\end{tabular}

* 数据来源于西藏自治区水产局 ${ }^{[32]}$; 鱼类市场价格按照 40 元 $/ \mathrm{kg}$ 计算; 年均开发价值按照 $1 / 10$ 开发量计算.

\section{4 参考文献}

[ 1 ] Yang HY, Huang DM. A preliminary investigation on fish fauna and resources of the upper and middle Yalu Tsangpo River. Journal of Huazhong Normal University: Nat Sci, 2011, 45(4): 629-633. [杨汉运, 黄道明. 雅鲁藏布江中上游鱼 类区系和资源状况初步调查. 华中师范大学学报: 自然科学版, 2011, 45(4): 629-633.]

[ 2 ] Ma BS. Study on the biology and population dynamics of Schizohorax o'connori [Dissertation]. Wuhan: Huazhong Agricul- 
tural University, 2011. [马宝珊. 异齿裂腹鱼个体生物学和种群动态研究 [学位论文]. 武汉: 华中农业大 学, 2011.]

[ 3 ] Zhou XJ. Study on the biology and population dynamics of Schizohorax waltoni [Dissertation]. Wuhan: Huazhong Agricultural University, 2014. [周贤君. 拉萨裂腹鱼个体生物学和种群动态研究 [学位论文]. 武汉: 华中农业大 学, 2014.]

[ 4 ] Huo B. Study on the biology and population dynamics of Oxygymnocypris stewartii [Dissertation]. Wuhan: Huazhong Agricultural University, 2014. [霍斌. 尖裸鲤个体生物学和种群动态学研究 [ 学位论文]. 武汉: 华中农业大学, 2014.]

[ 5 ] Yang X. Study on age, growth, feeding habits and population dynamics of Ptychobarbus dipogon in the Yarlung Tsangpo River [Dissertation]. Wuhan: Huazhong Agricultural University, 2014. [杨金金. 雅鲁藏布江双须叶须鱼年龄生长、食性 和种群动态研究 [学位论文]. 武汉: 华中农业大学, 2015.]

[ 6 ] Wang S, Xie Y eds. Red list of Chinese species: Vol I : Vertebrate. Beijing: Higher Education Press, 2004. [汪松, 解 炎. 中国红色名录 (第一卷: 脊椎动物, 上册). 北京: 高等教育出版社, 2004.]

[ 7 ] Shen HB, Guo L. Analysis and investigation of the fish from Niyang River, Tibet. Hebei Fisheries, 2008, 173( 5) : 51-54, 60. [沈红保, 郭丽. 西藏尼洋河鱼类组成调查与分析. 河北渔业, 2008, 173(5): 51-54, 60.]

[ 8 ] Fan LQ, Tu YL, Li JC et al. Fish assemblage at the Lhalu Wetland: does the native fish still exist. Resources Science, 2011, 33(9) : 1742-1749. [范丽卿, 土艳丽, 李建川等. 拉萨市拉鲁湿地鱼类现状与保护. 资源科学, 2011, 33 (9) : 1742-1749.]

[ 9 ] Chen F, Chen YF. Investigation and protection strategies of fishes of Lhasa River. Acta Hydrobiologica Sinica, 2010,34 (2)：278-285. [陈锋，陈毅峰. 拉萨河鱼类调查及保护. 水生生物学报, 2010, 34(2)：278-285.]

[10] Ding HP. Studies on the biology of exotic fishes in chabalang wetland and their stresses on native fishes [Dissertation]. Wuhan: Huazhong Agricultural University, 2014. [丁慧萍. 茶巴朗湿地外来鱼类的生物学及其对土著鱼类的胁迫 [学位论文]. 武汉: 华中农业大学, 2014.]

[11] Qin DH, Chen YY, Li XY et al eds. Climate and environment changes in China: Climate and environment changes in china and their projections. Beijing: Science Press, 2005: 98-109. [秦大河, 陈宜瑜, 李学勇等. 中国气候与环境演变 (下卷): 气候与环境变化的影响与适应、减缓对策. 北京: 科学出版社, 2005: 98-109.]

[12] Xie H. The Evapotranspiation and its response to climate change on the Tibetan plateau (1970-2010) [Dissertation]. Lanzhou: Lanzhou University, 2012. [谢虹. 青藏高原蒸散发及其对气候变化的响应(1970-2010) [学位论文]. 兰 州: 兰州大学, 2012.]

[13] An BS, Cheng GD. Dynamic analysis of the ecological footprint and carrying capacity of Tibet. Acta Ecologica Sinica, 2014, 34(4): 1002-1009. [安宝戟, 程国栋. 西藏生态足迹与承载力动态分析. 生态学报, 2014, 34(4): 1002-1009.]

[14] Li XQ, Chen YF, He DK. Reproductive strategy of Ptychobarbus dipogon in the Lhasa river, Xizang. Abstract assembly of seminar thesis from Chinese Ichthyological Scoiety in 2008, 2008. [李秀齐, 陈毅锋, 何德奎. 西藏拉萨河双须叶须鱼 的繁殖策略. 中国鱼类学会 2008 学术研讨会论文摘要汇编, 2008.]

[15] Guan ZH, Chen CY eds. River and lake in Tibet. Beijing: Science Press, 1984. [关志华, 陈传友. 西藏河流与湖泊. 北京: 科学出版社, 1984.]

[16] Han JY. Study on economical strategy about exploitation of the water resource in Tibet [Dissertation]. Xi'an: Shanxi Normal University, 2010. [ 韩俊宇. 西藏水资源开发的经济战略研究 [ 学位论文]. 西安: 陕西师范大学, 2010.]

[17] King J, Brown C, Sabet H. A scenario-based holistic approach to environmental flow assessments for rivers. River Research and Applications, 2002, 19(5/6): 619-639.

[18] Poff NL, Allan JD, Bain MB et al. The natural flow regime. Bioscience, 1997, 47(11) : 769-784.

[19] Postel S, Richter B eds. Rivers for life: Managing water for people and nature. Washington, D.C.: Island Press, 2003.

[20] Bunn SE, Arthington AH. Basic principles and ecological consequences of altered flow regimes for aquatic biodiversity. Environmental Management, 2002, 30(4): 492-507.

[21] Jiang ZG, Jiang JP, Wang YZ et al. Red list of China's vertebrates. Biodiversity Science, 2016, 24(5) : 500-551. [蒋志 刚, 江建平, 王跃招等. 中国脊椎动物红色名录. 生物多样性, 2016, 24(5): 500-551.]

[22] Fang GL, Xiang B, Du JQ et al. Risk assessment of non-point source pollution export in Lasahe basin. Transactions of the Chinese Society of Agricultural Engineering, 2015, 31(1): 247-254. [方广玲, 香宝, 杜加强等. 拉萨河流域非点源污 
染输出风险评估. 农业工程学报, 2015, 31(1): 247-254.]

[23] Ding HR. Research on total quantity of water pollutants in city areas of Lasa [Dissertation]. Chengdu: Sichuan University, 2005. [丁海容. 拉萨市城区段水环境污染总量控制研究 [学位论文]. 成都: 四川大学, 2005.]

[24] Zhou D, Huang CY. Current situation and pollution prevention and control measures of Lhasa River. Sichuan Water Conservancy, 2007, 2: 48-51. [周丹, 黄川友. 拉萨河流域水环境现状及污染防治对策. 四川水利, 2007, 2: 48-51.]

[25] Wang HL. Study on situation of water environment and protection countermeasure in Niyang River valley [Dissertation]. Lhasa: Tibet University, 2011. [王洪亮. 尼洋河流域水环境现状调查及保护对策研究 [学位论文]. 拉萨: 西藏大 学, 2011.]

[26] Wang YQ, Deng Xi, Luo HY. Cause of water environment deterioration and its countermeasures in rural region of Tibet. Western China Technology, 2007, 18: 32-34. [汪艳青, 邓欣, 罗红英. 西藏农村水环境恶化成因及治理对策. 中国 西部科技, 2007, 18: 32-34.]

[27] Zhang L. Geological characteristics of Yulong Copper Mine in Tibet and the environmental impact of minding [Dissertation]. Chengdu: Chengdu University of Technology, 2011. [张林. 西藏玉龙铜矿床地质特征及矿山开采对环境的影 响 [学位论文]. 成都: 成都理工大学, 2011.]

[28] Buduo, Xu ZY, Wujian ZX et al. Study on the impact of mineral processing plant on environment in Lhasa river catchment. Journal of Tibet University: Natural Science Edition, 2009, 24(2): 33-38. [布多, 许祖银, 吴坚扎西等. 拉萨河 流域选矿厂分布及其对环境的影响. 西藏大学学报: 自然科学版, 2009, 24(2): 33-38.]

[29] Luo W, Yang QF, Zhu GY et al. Study on water environmental impact assessment of landfill site in Tibet. Energy Environmental Protection, 2013, 27(5): 59-62. [罗文, 杨琼分, 朱国宇等. 浅析西藏高原地区生活垃圾填埋场水环境影响 评价. 能源环境保护, 2013, 27(5): 59-62.]

[30] Zhao ZR, Xie CQ, Dan Q et al. The valuation and dynamic forecast of ecological footprint of water resources in Tibet. Journal of Zhejiang University: Science Edition, 2015, 42(5) : 559-566. [ 赵忠瑞, 解传奇, 丹曲等. 西藏水资源生态足迹 评价与动态预测. 浙江大学学报: 理学版, 2015, 42(5) : 559-566.]

[31] Wu YF, Wu CZ eds. The fishes in Qinghai-Tibet Plateau. Chengdu: Sichuan Science and Technology Press. [武云飞, 吴 翠珍. 青藏高原鱼类. 成都: 四川科学技术出版社, 1991.]

[32] Bureau of Aquatic Products, Tibet Autonomous Region ed. Fish and fishery in Tibet. Beijing: China Agriculture Press, 1995. [西藏自治区水产局.西藏鱼类及其资源. 北京: 中国农业出版社，1995.]

[33] Chen YF, He DK, Cao WX et al. Growth of Selincuo Schizothoracini (Gymnocypris selincuoensis) in Selincuo Lake, Tibeten Platean. Acta Zoologica Sinica, 2002, 48(5) : 667-676. [陈毅峰, 何德奎, 曹文宣等. 色林错裸鲤的生长. 动 物学报, 2002, 48(5): 667-676.]

[34] Xinhua News Agency. http://news.xinhuanet.com/politics/2016-08/24/c_1119448608.htm. [新华社. [ 2016-08-24]. http://news.xinhuanet.com/politics/2016-08/24/c_1119448608.htm. ]

[35] Xinhua Online. http://www. zytzb. gov. cn/tzb2010/xzgzzth/zydlcxzgzzth.shtml. [ 新华网. [2015-08-24]. http://www. zytzb.gov.cn/tzb2010/xzgzzth/zydlcxzgzzth.shtml. ]

[36] Department of Agriculture's website. http://news.xinhuanet.com/politics/2016-03/29/c_128845434.htm. [农业部网站. [2016-03-29]. http://news.xinhuanet.com/politics/2016-03/29/c_128845434.htm.]

[37] China agricultural information network. http://www.gsny.gov.cn/apps/site/site/issue/ldjh/2016/07/15/1468568118931. html. [中国农业信息网. [ 2016-07-15 ]. http://www. gsny. gov. cn/apps/site/site/issue/ldjh/2016/07/15/ 1468568118931.html.]

[38] The Tibet Daily newspaper. http://tibet.news.cn/jujiao/20170103/3605413_c.html. [西藏日报. [2017-01-03].http:// tibet.news.cn/jujiao/20170103/3605413_c.html. ]

[39] Bureau of statistics of Tibet, National bureau of statistics Tibet survey team. 2016 Statistical yearbook of Tibet. Beijing: China Statistics Press, 2016, 28(28): 21, 162. [西藏自治区统计局, 国家统计局西藏调查总队. 2016 年西藏统计 年鉴. 北京: 中国统计出版社, 2016, 28(28): 21, 162.]

[40] You Y, Zhou YF, He WH et al. An analysis of the nutritive compositions in the muscle of Gymnocypris selincuoensi. Journal of Shanghai Ocean University, 2009, 18(2) : 2187-2192. [尤洋, 周彦锋, 何文辉等. 西藏色林错裸鲤肌肉营养 品质分析. 上海海洋大学学报, 2009, 18(2): 2187-2192.]

[41] Luosang, Buduo, Danzeng et al. Fatty acid composition and nutrition evaluation in muscle of three freshwater fishes. Fresh- 
water Fisheries, 2009, 39(6): 74-76. [洛桑, 布多, 旦增等. 3 种淡水鱼肌肉脂质的组成及营养评价. 淡水渔业, $2009,39(6): 74-76$.

[42] Deng JM, Zhang X, Long X et al. Analysis and evaluation of nutritional composition in muscle of three Schizothorax species. Acta Nutrimenta Sinica, 2013, 35(4): 391-393. [邓君明, 张䂀, 龙晓等. 三种裂腹鱼肌肉营养成分分析与评 价. 营养学报, 2013, 35(4): 391-393.]

[43] Liu JK et al eds. Advanced hydrobiology. Beijing: Science Press, 1999. [刘建康等. 高级水生生物学. 北京: 科学出版 社, 1999.]

[44] Li HJ. Studies on the biology and population ecology of Glyptosternum maculatum (Regan) in the Brahmaputra River, China [Dissertation]. Wuhan: Huazhong Agricultural University, 2008. [李红敬. 黑斑原鮡个体生物学及种群生态研究 [学位论文]. 武汉: 华中农业大学, 2008.]

[45] Ji Q. The study on the morphology of feeding organs and the feeding habits of six Schizothoracine fishes [Dissertation]. Wuhan: Huazhong Agricultural University, 2008. [季强. 六种裂腹鱼类摄食消化器官形态学与食性的研究 [ 学位论 文]. 武汉: 华中农业大学, 2008.]

[46] Zhu XF, Chen YF. Preliminary study on the age and growth characteristics of Schizothorax macropogon. Chinese Journal of Zoology, 2009, 44(3) : 76-82. [ 朱秀芳, 陈毅峰. 巨须裂腹鱼年龄与生长的初步研究. 动物学杂志, 2009, 44(3): 76-82.]

[47] Dua YJ. Study on the biology and population dynamics of Schizopygopsis younghusbandi [Dissertation]. Wuhan: Huazhong Agricultural University, 2011. [段友健. 拉萨裸裂尻鱼个体生物学和种群动态研究 [学位论文]. 武汉: 华中农业大 学, 2015.]

[48] Ma XH. The phylogeny, biogeograph and adaptive evolution of Chinese Sisoridae fishes. Chongqing: Xinan University, 2015. [马秀慧. 中国鮡科鱼类系统发育、生物地理及高原适应进化研究 [ 学位论文]. 重庆: 西南大学, 2015.]

[49] Li LT. Study on age, growth and population dynamics of Triplophysa orientalis in the Yarlung Tsangpo River [Dissertation]. Wuhan: Huazhong Agricultural University, 2016. [李亮涛. 雅鲁藏布江中游东方高原鲀年龄生长和种群动态 研究 [ 学位论文]. 武汉: 华中农业大学, 2016.]

[50] Liu HP, Ye SW, Yang XF et al. Spatio-temporal characteristics of aquatic organism community and their relationship to environment in Niyang River, the branch of Yarlung Zangbo River, Tibet:1. Phytoplankton. J Lake Sci, 2013, 25( 5) : 695-706. DOI: 10.18307/2013.0511. [刘海平, 叶少文, 杨学峰等. 西藏尼洋河水生生物群落时空动态及与环境因 子关系: 1.浮游植物. 湖泊科学, 2013, 25(5): 695-706.]

[51] Liu HP, Ye SW, Yang XF et al. Spatio-temporal characteristics of aquatic organism community and their relationship to environment in Niyang River, the branch of Yarlung Zangbo River, Tibet:2. periphytic algae. J Lake Sci, 2013, 25(6) : 907-915. DOI: 10.18307/2013.0615. [刘海平, 叶少文, 杨学峰等. 西藏尼洋河水生生物群落时空动态及与环境因 子关系:2. 着生藻类. 湖泊科学, 2013, 25(6): 907-915.]

[52] Liu HP, Ye SW, Yang XF et al. Spatio-temporal characteristics of aquatic organism community and their relationship to environment in Niyang River, the branch of Yarlung Zangbo River, Tibet:3. macrozoobenthos. J Lake Sci, 2014, 26(1) : 154-160. DOI: $10.18307 / 2014.0119$. [刘海平, 叶少文, 杨学峰等. 西藏尼洋河水生生物群落时空动态及与环境因 子关系:3.大型底栖动物, 湖泊科学, 2014, 26(1): 154-160.]

[53] Liu HP, Ye SW, Zhong GH et al. Multivariate statistical analysis of physical and chemical properties of water quality from Niyang River, the branch of the Yarlung Zangbo River, Tibet. J Lake Sci, 2015, 27 (6) : 1187-1196. DOI: 10.18307/ 2015.0625. [刘海平, 叶少文, 钟国辉等. 西藏尼洋河水环境特征多元统计分析. 湖泊科学, 2015, 27 (6): 1187-1196.]

[54] Liu HP, Ye SW, Yang XF et al. Spatio-temporal characteristics of aquatic organism community and their relationship to environment in Niyang River, the branch of Yarlung Zangbo River, Tibet:4. zooplankton. J Lake Sci, 2014, 28(2) : 370378. DOI: $10.18307 / 2016.0217$. [刘海平, 叶少文, 杨学峰等. 西藏尼洋河水生生物群落时空动态及与环境因子关 系: 4. 浮游动物. 湖泊科学, 2016, 28(2): 370-378.]

[55] Liu HP, Ye SW, Yang XF et al. Spatio-temporal variability of periphytic protozoa related to environment in Niyang River, Tibet, China. Chinese Journal of Oceanology and Limnology, 2017, 35(3) :1-12.

[56] Wu X. Innovation of agricultural investment management mechanism, strengthening the building of infrastructure. China Economic \& Trade Herald, 2016, 6: 60-62. [ 吴晓. 创新农口投资管理机制, 加强农村基础设施建设. 中国经贸导刊, 
2016, 6: 60-62.]

[57] Li GX. Supply-side reform and the transformation and upgrading of agricultural development in China. Agri-economy, 2016，(1)：24-25. [李国祥. 供给侧改革与我国农业发展转型升级. 农经, 2016, (1) : 24-25.]

[58] China Tibet news network. http://www.chinatibetnews.com/zw/qwfb/201604/t20160423_1194980.html. [中国西藏新 闻网. [2016-04-23]. http://www.chinatibetnews.com/zw/qwfb/201604/t20160423_1194980.html.]

[59] Zhu TB, Liu HP, Li XM et al. Status and problems of fish stock enhancement in Tibet. Freshwater Fisheries, 2017,47 (5) : 34-39. [ 朱挺兵, 刘海平, 李学梅等. 西藏鱼类增殖放流初报. 淡水渔业, 2017, 47 (5): 34-39.]

[60] National aquaculture stock seed and certified seed examination committee website. http://nccav. moa. gov.cn/news-show. asp? anclassid $=129 \&$ nclassid $=34 \& x$ classid $=0 \& i d=2395$. [ 全国水产原种和良种审定委员会网站. [ 2015-10-30 ]. http : / /nccav. moa.gov.cn/news-show. asp? anclassid = 129\&nclassid $=34 \&$ xclassid $=0$ \&id $=2395$. ]

[61] Central People's Government of the People's Republic of China website. http://www.gov.cn/zhengce/content/2016-12/ 05/content_5143290.htm. [中华人民共和国中央人民政府网站. [2016-11-24]. http://www.gov.cn/zhengce/content/ 2016-12/05/content_5143290.htm. ]

[62 ] Xu J. Study on age, early development of four Schizothoraeinae fishes in Yarlung Zangbo River, Tibet [Dissertation]. Wuhan: Huazhong Agricultural University, 2011. [许静. 雅鲁藏布江四种特有裂腹鱼类早期发育的研究 [学位论文]. 武汉: 华中农业大学, 2011.]

[63] Shao J. Study on the cultivation biology of four endemic fishes in the plateau [Dissertation]. Wuhan: Huazhong Agricultural University, 2016. [邵俭. 四种高原土著鱼类养殖生物学研究 [学位论文]. 武汉: 华中农业大学, 2016.]

[64] Wang F. Studies on several culture biology characteristics of Salmotrutta [Dissertation]. Shanghai: Shanghai Ocean University, 2015. [王芳. 亚东鲑若干养殖生物学特性研究 [ 学位论文]. 上海: 上海海洋大学, 2015.]

[65] Grime JP. Competitive exclusion in herbaceous vegetation. Nature, 1973, 242(5396) : 344-347.

[66] Connell JH. Diversity in tropical rain forests and coral reefs-high diversity of trees and corals is maintained only in a non-equilibrium state. Science, 1978, 199(4335) : 1302-1310.

[67] The Tibet Daily newspaper. http://leaders.people.com.cn/n1/2016/0206/c58278-28115896.html. [西藏日报. [201602-06]. http://leaders.people.com.cn/n1/2016/0206/c58278-28115896.html. 